\title{
Alcohol and Tobacco Use Among Women Who Have Sex With Women
}

Cort M. Dorn-Medeiros ${ }^{1}$

Lewis and Clark College

Cass Dykeman

Oregon State University

Timothy Bergquist

Northwest Christian University

A preprint. This manuscript may contain errors or omissions not present in a final published copy of record. The copy of record can be found at: https://www.counseling.org/knowledge-center/vistas/by-year2/vistas2016/docs/default-source/vistas/article_87_2016

\begin{abstract}
Evidence suggests that women who report same-sex partners may be at particular risk for experiencing negative health effects from alcohol and tobacco use. Using data pooled from the results of the 2008-2013 New York City Community Health Survey, this study used multiple regression analyses to examine the predictability of annual household income, age, race, and history of depression on frequency and quantity of alcohol and tobacco use within a total sample of women who have sex with women (WSW). Age and history of depression were statistically significant predictors of alcohol use in WSW, and race was a statistically significant predictor of tobacco use with non-Hispanic White respondents. Results of this study provide greatly needed insight into possible risk factors for alcohol and tobacco use among a significantly understudied population. Results also provide strong encouragement for counselors to inquire about sex and sexuality regardless of client self-identified sexual orientation.
\end{abstract}

Keywords: substance use, tobacco, alcohol, women, sexuality, lesbian.

1. Correspondence concerning this article should be addressed to Cort M. Dorn-Medeiros at dorn-medeiros@lclark.edu 


\section{Alcohol and Tobacco Use Among Women Who Have Sex With Women}

Elevated use of alcohol and tobacco is a major public health risk in the United States (McGinnis \& Foege, 1999; Murray, Istvan, Daniels, \& Beaudoin, 1998; Substance Abuse and Mental Health Services Administration [SAMHSA], 2014). Using substances at increased rates of frequency and quantity negatively impacts relationships with family and friends and the ability to sustain various life roles. Many past studies on substance use among individuals who report having same-sex partners frequently use male populations as study samples (Lee \& Crawford, 2007). In addition, a majority of research conducted on males who report samesex partners is conducted in relation to public health research around the health implications of drug use (Jerome \& Halkitis, 2009). Little research exists similarly focusing on substance use among women who report same-sex partners.

One practical challenge that comes with studying females who report same-sexpartners is that rarely are sexual practices asked about in research on substance use that does not exclusively focus on individuals who identify as gay, lesbian, or bisexual. As such, the population of women who have sex with women (WSW) is often an invisible minority. While we know, for example, that certain risk factors for problematic substance use exist, such as income level, age, and co-occurring mental health issues, we do not know much about the relationship between these factors in substance use within populations of WSW. This paper is intended to contribute to the current literature and knowledge base within the counseling profession. Specifically, this work seeks to address topics related to multicultural counseling and counseling related to alcohol, drug, and tobacco usage. The American Counseling Association (ACA) Code of Ethics (2014) requires counselors and counseling students to work with a vast array of potential clients who may differ significantly from themselves. For example, these counselor and client differences can include one or several factors such as age, race, ethnicity, ability status, socioeconomic status, sexual orientation, and gender identity. As part of building up counselor competency to work with diverse individuals, counselors and counseling students are required to seek out relevant literature as it relates to appropriate assessment, intervention, and advocacy for their clients (ACA, 2014). 
Likewise, SAMHSA requires counselors and counselor supervisors within the substance use counseling specialty to attend to issues of diversity within the counselorclientrelationship, but also within the supervisorsupervisee relationship. Additionally, substance use counseling supervisors are required to provide or coordinate appropriate and relevant supervisee training as needed related to issues of diversity to empower counselors to better advocate for both individual client needs and organizational change when appropriate (SAMHSA, 2014).

As part of a commitment to explore issues related to multicultural counseling and contribute to relevant literature, this research and the resulting paper seek to address a population that often goes unnoticed and slips through the cracks of researcher consciousness. Few research studies that explore issues related to substance use or substance use as it relates to sexuality focus exclusively on female-identified populations. As such, WSW often go unnoticed within study populations and become an invisible minority.

In addition to addressing issues related to highlighting this invisible minority, the rationale behind utilizing inclusion criterion based upon participant-reported sexual Ideas and behavior, and not self-reported sexual identity such as lesbian or bisexually identified women, is twofold. One, a logical assumption is that there is likely a significant overlap among women who self-identify as lesbian or bisexual who also report having had sexwith other women. Second, there is current literature that points to a significant discrepancy between sexual behavior and selfreported sexual identity (Pathela et al.,2006). In other words, many individuals who report having same-sex sexual encounters do not identify as gay, lesbian, or bisexual. It is important to note that these studies on sexual behavior and identity discrepancies tend to predominantly discuss male populations. There is little literature available on the prevalence of this discrepancy among female populations.

Some evidence suggests that women who report same-sex partners may be at elevated risk for experiencing negative health effects from alcohol, tobacco, and other substance use (Boehmer, Miao, Linkletter, \& Clark, 2012; Cochran \& Mays, 2007).While existing evidence is not always consistent (Cochran, Mays, \& Sullivan, 2003; Roberts \& Sorenson, 1999), women who report same-sex partners may be more likely to be current or former smokers and report higher levels of alcohol use compared to 
women reporting exclusively male partners. (Burgard, Cochran, \& Mays, 2005; Gruskin, Byrne,Kools, \& Altschuler, 2007).

The intention of this exploratory study was not to disregard the importance of sexual identity and the personal, social, and political implications therein. For example, there are demonstrated differences in health outcomes for lesbian-identified women versus bisexually-identified women (Fredriksen-Goldsen, Kim, Barkan, Balsam, \&Mincer, 2010). Research on substance use rates broken down between queer-identified and other sexual identity categories within female populations is sparse to say the least. It should be noted that collapsing multiple groups of varying sexual identities among women into one sample population based strictly on behavior, rather than personal identity, is a limitation of this study that will be discussed below.

Specific demographic variables are known to be associated with increased risk of problematic substance use among women. For example, there is a strong association between socioeconomic disadvantage and problematic alcohol, drug, and tobacco use(Redonnet, Chollet, Fombonne, Bowes, \& Melchior, 2012). Poverty, substandard housing, and lower levels of educational grade completion all likely increase the risk of problematic drinking, heavier tobacco use, and illicit drug use (Booth, Bildner, \& Bozzo,2001; National Center on Addiction and Substance Use, 2000). According to a 2013 study by the Williams Law Institute at UCLA, lesbian and bisexual women may be more likely to live off lower incomes and experience poverty than heterosexual women. According to the study, $14.1 \%$ of lesbian couples were receiving food stamps compared to $6.5 \%$ of heterosexual couples, and $2.2 \%$ of couples with same-sex partners were receiving government cash assistance compared to $.8 \%$ with opposite-sex partners (Badgett, Durso, \& Schneebaum, 2013).

Among different age groups, adolescents and younger people, including transitional adults, may be at elevated risk of experiencing problematic substance use (Choquet, Morin, Hassler, \& Ledoux, 2004; Merline, O'Malley, Schulenberg, Bachman,\& Johnston, 2004). According to results of the National Survey of Drug Use and Health (NSDUH; SAMHSA, 2014), transitional-aged youth of 18-25 indicated higher percentages of alcohol use $(76.50 \%)$ and cigarette use $(37.70 \%)$ over the past year than youth aged $12-17(24.00 \%$ and $8.9 \%$ respectively) and adults over the age of 25 (70.10\%and $24.60 \%$ respectively). In the United States, risk of 
substance use may also be higher among youth and young adults who come from a lower socioeconomic bracket and lower-income households (Windle, Mun, \& Windle, 2005).

Additionally, youth and young adults who identify as gay, lesbian, or transgender also evidence increased use when compared to heterosexually-identified peers (Bontempo \& D'Augelli, 2002; McLaughlin, Hatzenbuehler, Xuan, \& Conron, 2012).Additional results from the 2013 NSDUH (SAMHSA, 2014) indicate that those who identified as White were more likely than those of any other race/ethnicity to report current use of alcohol (57.7\%). The prevalence of current tobacco use was highest for American Indians or Alaska Natives (40.1\%). It is important to note that these rates are reported across gender identities and are not further broken down by sexual identity or sexual behavior practices. There is little research looking at the intersectionality of a multitude of difference demographic variables, including age, race, income level, and sexual identity or sexual behavior practices.

Alongside the aforementioned demographic variables of income level, age, and racial identity related to alcohol and tobacco use, certain behavioral variables have also been shown to potentially increase the risk of problematic use. More specifically, issues with mental and behavioral health have been associated with a greater likelihood of elevated alcohol, tobacco, and other substance use. Depression is one of the most commonly cited mental health disorders associated with a co-occurring substance use disorder, with higher levels of depressive symptoms most commonly reported among individuals reporting heavier rates of alcohol use (Grant, 1995; Grant \& Harford, 1995; Paschall, Freisthler, \& Lipton, 2005; Regier et al., 1990). As sexual orientation and sexual practices are often not asked about in large scale studies looking exclusively at episodes of depression, exact prevalence numbers of depression among WSW are not yet known. However, WSW have been estimated to experience episodes of major depressive disorder (MDD) roughly 2.7 times more than other women (Gilman et al., 2001).

Utilizing data from the 2008-2013 New York City Community Health Survey (NYCCHS; New York City Department of Health and Mental Hygiene, 2008-2013), this exploratory study was designed to determine the correlation and predictability of respondent self-reported annual household income, age, history of depression, and racoon levels of alcohol 
and tobacco use among female-identified respondents who also reported having same-sex partners within the past year. The goal of this research was to further explore the possible correlation between the aforementioned variables and frequency and quantity of alcohol and tobacco use within a sample of WSW.

\section{Method}

\section{Design}

This study utilized a retrospective cross-sectional observational design following the STROBE protocol (Jepsen, Johnsen, Gillman, \& Sørensen, 2004; Mann, 2003; Vandenbroucke et al., 2007). Data were collected from female-identified respondents of the New York City Community Health Survey (NYCCHS) between the years 2008 and 2013. The NYCCHS is an annual telephone survey conducted by the New York City Department of Health and Mental Hygiene (DOHMH) Division of Epidemiology, Bureau of Epidemiology Services. Interviews are conducted in English, Spanish, Russian, and Chinese (Mandarin and Cantonese). All data are selfreported. Prior to data collection, a power analysis was conducted using G*Power 3.1(Faul, Erdfelder, Buchner, \& Lang, 2009). The test family was: $\mathrm{F}$ tests. The statistical test was: linear multiple regression: fixed model, R2 deviation from zero. The type of power analysis was: a priori: compute required sample size, given $\alpha$, power, and effect size. The effect size was drawn from data reported by Harned, Najavits, and Weiss (2006). The G*Power 3.1 output included a sample size of 121 and an actual power of 0.95 .

\section{Participants}

Analyses were limited to female-identified respondents who completed the sexual partner history question. Data were obtained from the NYCCHS years 2008-2013 and pooled together to include a sufficient sample. The range in years for data inclusion was selected to provide a more robust sample of WSW for sufficient statistical power. The sample of 547 respondents ranged in age from 18 to 83 . The respondent sample was racially and ethnically diverse, with 341 of the total sample identifying as non-White, 136 identifying as Black or African American, 167 as Hispanic or Latino, 19 as Asian American or Pacific Islander, 206 as non-Hispanic White, and 19 as Other. In terms of sexual orientation, 283 identified as 
lesbian, 83 as bisexual, and 168 as heterosexual, and10 did not answer and 3 refused.

\section{Measures}

The NYCCHS is a cross-sectional telephone health surveillance survey of adult New Yorkers and has been conducted annually since 2002 by the city's Department of Health and Mental Hygiene. The NYCCHS content is redesigned each year, while maintaining some core health and demographic questions. A variety of questions that have been included on the NYCCHS have come from other large surveys, including the Behavioral Risk Factor Surveillance Survey, the National Health and Nutrition Examination Survey, the National Health Interview Survey, and the National Survey on Drug Use and Health. Each year, the Bureau of Epidemiology Services also works with programs to develop new questions (when previously validated questions are not available).

All NYCCHS participants were asked about sexual behavior. Participants were specifically asked about their sexual partners over the prior 12 months and within their lifetime. Included participants answered "at least one" to the survey question, "During the past 12 months, with how many women have you had sex?" or answered affirmatively to the survey question, "Have you ever had sex with a woman?" Regarding the predictor variables included for correlation and linear regression, respondents were asked to provide their age, racial identity, and range of annual household income. The independent variable of history of depression was taken from a survey question specifically asking respondents if a medical provider had told them they had depression.

The first criterion variable of alcohol use was measured by two survey questions, one asking respondents on how many days they consumed a drink containing alcohol and two, how many drinks containing alcohol they consumed on days they would drink. The second criterion variable of tobacco use was also measured by two questions, one asking respondents if they smoked every day, some days, or not at all and, two, how many Ideas and they smoked per day. Respondents who answered affirmatively to either smoking every day or some days were included in the study data. All survey questions, with the exception of age, allowed for a response of either Unsure or Refused to Answer. All survey questions 
utilized for this study can be found in full text online (New York City Department of Health and Mental Hygiene, 2008-2013).

\section{Procedures}

De-identified data were obtained from the NYCCHS for inclusion in this study. All relevant data, including predictor and criterion variables, from the survey years 2008-2013 were pooled together into a Microsoft Excel document prior to data analysis. Before data pooling, the survey document itself for each year was examined to account for differences in numeration or question placement in the multiple surveys. This process was also completed to confirm consistency in question structure and response options for relevant portions throughout the years. Next, the data was cleaned via examination for non-responses of any of the predictor or criterion variables. Respondents included in this study needed to provide an answer for all relevant predictor variables. As a point of clarification regarding criterion variables, respondents could answer affirmatively for consuming alcohol but not tobacco and vice versa. Respondents included for participation did not need to answer affirmatively for both alcohol and tobacco consumption. However, both questions that constituted each criterion variable as listed in the prior section needed to be answered for inclusion.

\section{Data Analysis}

Multiple regression analyses were performed on each criterion variable to determine the predictability of annual household income, age, history of depression, and racial identity on alcohol use and tobacco use within the sample of WSW. All statistical analyses were performed using Microsoft Excel 2010, version 14.6.3. While not a particularly powerful or flexible tool for regression, Microsoft Excel was chosen to complete data analysis primarily for reasons of accessibility. The problems relevant to this statistical tool are discussed below as part of limitations of this study.

Stepwise backward regression analyses were used to analyze the study data. This process was selected to determine the amount of variance in means of the criterion variables of alcohol use and tobacco use while accounting for any possible influence of the predictor variables of age, annual household income, race or history of depression. This procedure was also selected to eliminate the previously selected predictor variables 
from the model as they were shown to have a non-significant effect on the respective criterion variable (Chung \& Mezei, 1999; Rinne et al., 2002). This process begins with all predictor variables in the model and then removes them one at a time if not significant.

A correlational matrix was first run to identify which of the four predictor variables had the highest correlation with the criterion variables of alcohol use (Table 1) and tobacco use (Table 2). All variables were then entered into the regression model. The $t$ statistic was first calculated for each variable in the model for its approximate coefficient and then squared to obtain the $R^{2}$ value for alcohol use (Table 3) and tobacco use (Table 4). Variables were then removed from the regression model based on the Ideas and statistical significance of the correlation coefficient at $p<.05$. The regression was then run a second time only including the significant variables. As suspected only the variables with the highest correlation, age, and history of depression on alcohol use and race on tobacco use, were significant.

\section{Results}

A total of 547 WSW were obtained as an initial sample population between all years 2008-2013. Following data cleaning procedures, a total of 509 WSW were included in the first research question looking at alcohol use, and a total of 114 Swire included in the second research question looking at tobacco use. As expected, there was a significant amount of overlap between sexual identity and sexual behavior, with366 (approximately 67\%) of the total sample of WSW also identifying as lesbian or bisexual.

The initial data review included an observation of means, standard deviations, and correlations among all predictor and criterion variables. Pearson product-moment correlation was utilized to determine the interdependence between each of the four predictor variables and the two criterion variables of alcohol use and tobacco use.

In terms of predictor variables and alcohol use, the initial run of the full model regression utilizing all four predictor variables resulted in $R^{2}=$ 0.056 , or roughly $5.6 \%$ of the total variance in alcohol use could be accounted for by age, annual household income, race, and history of 
depression. In the full model, race was found to provide the least explanatory power $(p=0.6250)$ followed by annual household income $(p=$ $0.6018)$.Bivariate correlations indicated higher levels of alcohol use were negatively associated with the predictor variables of age $(r=-0.215, p<.05)$ and history of depression $(r=-0.104, p<.05)$. The additional predictor variables of race $(r=0.019, p>.05)$ and annual household income $(r=-$ $0.021, p>.05)$ were not found to be significantly associated with alcohol use. The second model run with only the significant variables of age and history of depression resulted in $R^{2}=0.0548$, or approximately $5.5 \%$ of the variance was accounted for by the two significant variables. In terms of the predictor variables and tobacco use, the initial run of the full model regression utilizing all four predictor variables resulted in $R^{2}=0.069$ or roughly $6.9 \%$ of the total variance in tobacco use could be accounted for by age, annual household income, race and history of depression. The initial bivariate correlations showed only a significant negative association between the predictor variable of race $(r=-0.216, p<.05)$ and tobacco use. Additional predictor variables of age $(\mathrm{r}=0.072, \mathrm{p}>.05)$, annual household income $(r=0.003, p>.05)$ and history of depression $(r=-0.113, p>.05)$ were not found to have a significant association with the criterion variable of tobacco use. The second model run with only the significant variable of race resulted in $R^{2}=0.0468$, or approximately $4.7 \%$ of the variance in tobacco use was accounted for by the significant variable of race.

Multiple regression analysis was then performed for both alcohol and tobacco use to determine the amount of unique variance in alcohol use and tobacco use, respectively, when accounting for the variables of age, annual household income, race, and history of depression within the sample of WSW. In terms of alcohol use among WSW, there was a predictive relationship between the variables of age and history of depression. Both of these variables were negatively associated with the criterion variable of self-reported alcohol use meaning as age increased, alcohol use decreased, and as score of the survey question of history of depression increased $(1=$ yes, $2=$ no), alcohol use decreased. These results indicate that respondents who reported they had been told they have depression overall reported higher levels of alcohol use than those who had not been told they had depression. There was no predictive relationship between race and annual household income and alcohol use within the sample population. 
In terms of tobacco use among WSW, there was a predictive relationship between the variable of race and level of tobacco use. These results indicate respondents who identified as White reported higher levels of tobacco use than those who identified as non-White. There was no predictive relationship found between age, annual household income, and history of depression with tobacco use.

\section{Discussion}

The results of this study provide mixed support for the current body of research on substance use within the general population and within sexual minority populations. In regards to alcohol use, results indicated that age and history of depression were the only criterion variables that proved statistically significant as predictors of alcohol use in WSW. Specifically, as age increased, alcohol use decreased. A respondent's indication that a medical provider had told her that she was depressed was also predictive of alcohol use. The significance of these two variables supports a substantial amount of literature indicating adolescents and younger adults tend to report greater frequency and quantity of alcohol use than older individuals (Choquet et al., 2004; Hughes \& Eliason, 2002).

In a similar fashion, research has long supported the connection between substance use and mental health issues. Depression, in particular, has been strongly associated with increased use of alcohol and other substances (Foulds et al., 2015). Although this relationship may be said to be somewhat cyclical in nature, the idea that individuals who consume alcohol in an attempt to mitigate symptoms of depression in a variety of populations is certainly not new (Jakupcak et al., 2010).

In terms of tobacco use among WSW, results indicated race was the only significant predictor of tobacco use with respondents identifying as White being more likely to use tobacco than those identifying as non-White. Current literature on sexual minority populations shows women who report same-sex partners and other non-heterosexually identified women to be more likely to report tobacco use or to identify as being smokers (Cochran et al., 2001; Gruskin, Byrne, Altschuler, \& Dibble, 2009; Gruskin et al., 2007). Additionally, non-Hispanic White men and women may indicate higher rates of tobacco use than many other racial identities, including Black or African American, Hispanic, and Asian (Cornelius, Lynch, Martin, Cornelius, \& Clark, 2001; SAMHSA, 2014). However, 
literature is mixed on White-identified women, or even broken down further, White-identified women who report same-sex partners either misbehavior or sexual identity, using tobacco at higher rates than other racial identities. More research is needed in this area.

In summary, younger WSW with histories of depression were more likely to consume alcohol in quantity and frequency. These results are of particular interest to counselors as sexual behavior may often not be directly asked about during client intake, assessment, or throughout the counseling process. While the counseling field has progressed in terms of adding items such as sexual orientation or, occasionally, gender identity on intake forms, questions of direct sexuality can often still be seen as taboo or rude. The topic of sex is often relegated to couples counseling or puts the onus on the client to bring it up. Counselors also run the risk of assuming sexual behavior and sexual identity or orientation are one in the same. As the initial results of this study demonstrate, many women who reported a heterosexual orientation also reported having sex with another woman. And not just a few outliers -168 women, out of the total sample of 547 (or approximately $31 \%$ of the sample population) identified as heterosexual but reported having sex with at least one other woman. That number represents a substantial percentage of women who demonstrate a perceived discrepancy between their sexual orientation and the assumed sexual behavior. If anything, those results push counselors to resist this assumption of congruency between sexual orientation and behavior. Discrepancy between sexual orientation and sexual behavior, and counselor awareness and response to such discrepancy, is an area ripe for future research.

The results of this study contain several limitations. As previously mentioned, Microsoft Excel contains a number of shortcomings in regression analyses. What it gains in accessibility it lacks in power and flexibility. The results of the current study could be greatly strengthened by re-running the regression analyses in a more advanced statistical program that would allow for better control. Additionally, the current sample of WSW of547 greatly surpasses the sample requirement of 121 for adequate power. Overpowered results can derive from the use of large sample sizes that can potentially detect a statistical difference, or provide a "positive" result when none actually exists (Ellis, 2010; Hochster, 2008). 
While the NYCCHS is sufficient for transferability and generalizability to the New York City area and its residents, one must remain cautious in generalizing to other populations and communities across the country. It is important to note that while providing for a significantly large sample size, a public health survey out of New York City may contain significant discrepancy with a similar survey out of, for example, a small town in the deep southern part of the United States. Future studies looking at this topic in smaller and more rural communities from different areas of the United States and even across the globe would greatly strengthen the results of the current study.

Finally, the multiple regression technique chosen to analyze data also provides its own limitations around study interpretation. Multiple regression analysis can only determine relationships, or correlations, between variables. Even if a strong relationships found between two or more variables in a multiple regression analysis, it does not imply influence or causality between variables.

In conclusion, the results of this study indicate that age and history of depression are significant predictors of alcohol use, and race is a significant predictor of tobacco use among a sample of WSW in New York City. While the limitations of this study inhibit the ability to speak to causality between and among these variables, the results do provide some insight into possible risk factors for alcohol and tobacco use among a greatly understudied population. It is strongly recommended that counselors ask not only about alcohol and tobacco use, which is hopefully more standard protocol in modern times omental health care, but also about sex and sexuality regardless of client sexual orientation. Counselors are strongly encouraged, or some may say even ethically responsible, to resist the urge to assume. Future research would particularly benefit from continuing to examine the intersection of sexual behavior, sexual identity, and substance use. 


\section{References}

American Counseling Association. (2014). ACA code of ethics. Alexandria, VA: Author. Badgett, M. V., Durso, L. E., \& Schneebaum, A. (2013). New patterns of poverty in the lesbian, gay, and bisexual community. Retrieved from the Williams Institute website: http://williamsinstitute.law.ucla.edu/research/census-lgbtdemographicsstudies/lgbt-poverty-update-june-2013/

Boehmer, U., Miao, X., Linkletter, C., \& Clark, M. A. (2012). Adult health behaviors over the life course by sexual orientation. American Journal of Public Health, 102(2), 292-300. doi:10.2105/AJPH.2011.300334

Bontempo, D., \& D'Augelli, A. (2002). Effects of at-school victimization and sexual orientation on lesbian, gay, or bisexual youths' health risk behavior. Journal of Adolescent Health, 30, 364-374. http://dx.doi.org/10.1016/S1054-139X(01)00415-3

Booth, K., Bildner, D., \& Bozzo, R. (2001). Substance abuse and welfare recipients in the rural setting. Rural Welfare Issues Brief. Calverton, MD: ORC Macro.

Burgard, S. A., Cochran, S. D., \& Mays, V. M. (2005). Alcohol and tobacco use patterns among heterosexually and homosexually experienced California women. Drug and Alcohol Dependence, 77(1), 61-70.

Choquet, M., Morin, D., Hassler, C., \& Ledoux, S. (2004). Is alcohol, tobacco, and cannabis use as well as polydrug use increasing in France? Addictive Behaviors, 29(3), 607-614. http://dx.doi.org/10.1016/j.addbeh.2003.08.047

Chung, F., \& Mezei, G. (1999). Factors contributing to a prolonged stay after ambulatory surgery. Anesthesia \& Analgesia, 89(6), 1352. doi:10.1213/00000539-199912000-00004

Cochran, S. D., \& Mays, V. M. (2007). Physical health complaints among lesbians, gay men, and bisexual and homosexually experienced heterosexual individuals: results from the California Quality of Life Survey. American Journal of Public Health, 97(11), 2048-2055.

Cochran, S. D., Mays, V. M., Bowen, D., Gage, S., Bybee, D., Roberts, S. J. . .. White, J.(2001). Cancer-related risk indicators and preventive screening behaviors among lesbians and bisexual women. American Journal of Public Health, 91(4), 591-597.

Cochran S., Mays V., \& Sullivan J. (2003). Prevalence of mental disorders, psychological distress, and mental health services use among lesbian, gay, and bisexual adults in the United States. Journal of 
Consulting and Clinical Psychology, 71(1), 53-61. doi:10.1037/0022006X.71.1.53

Cornelius, J. R., Lynch, K., Martin, C. S., Cornelius, M. D., \& Clark, D. B. (2001).Clinical correlates of heavy tobacco use among adolescents. Addictive Behaviors, 26(2), 273-277. http://dx.doi.org/10.1016/S03064603(00)00088-5

Ellis, P. D. (2010). The essential guide to effect sizes: Statistical power, metaanalysis, and the interpretation of research results. New York, NY: Cambridge University Press.

Faul, F., Erdfelder, E., Buchner, A., \& Lang, A. G. (2009). Statistical power analyses using $\mathrm{G}^{*}$ Power 3.1: Tests for correlation and regression analyses. Behavior Research Methods, 41, 1149-1160. doi:10.3758/BRM.41.4.1149

Foulds, J. A., Douglas Sellman, J., Adamson, S. J., Boden, J. M., Mulder, R. T., \& Joyce,P. R. (2015). Depression outcome in alcohol dependent patients: An evaluation of the role of independent and substanceinduced depression and other predictors. Journal of Affective Disorders, 174, 503-510. http://dx.doi.org/10.1016/j.jad.2014.11.052

Fredriksen-Goldsen, K. I., Kim, H. J., Barkan, S. E., Balsam, K. F., \& Mincer, S. L.(2010). Disparities in health-related quality of life: a comparison of lesbians and bisexual women. American Journal of Public Health, 100(11), 2255-2261.

Gilman, S. E., Cochran, S. D., Mays, V. M., Hughes, M., Ostrow, D., \& Kessler, R. C.(2001). Risks of psychiatric disorders among individuals reporting same-sex sexual partners in the National Comorbidity Survey. American Journal of Public Health, 91, 933-939.

Grant, B. F. (1995). Comorbidity between DSM-IV drug use disorders and major depression: Results of a national survey of adults. Journal of Substance Abuse, 7(4), 481-497. http://dx.doi.org/10.1016/08993289(95)90017-9

Grant, B. F., \& Harford, T. C. (1995). Comorbidity between DSM-IV alcohol use disorders and major depression: Results of a national survey. Drug and Alcohol Dependence, 39(3), 197-206. http://dx.doi.org/10.1016/0376-8716(95)01160-4

Gruskin, E. P., Byrne, K. M., Altschuler, A., \& Dibble, S. L. (2009). Smoking it all away: Influences of stress, negative emotions, and stigma on lesbian tobacco use Journal of LGBT Health Research, 4(4), 167-179. doi:10.1080/15574090903141104 
Gruskin, E., Byrne, K., Kools, S., \& Altschuler, A. (2007). Consequences of frequenting the lesbian bar. Women \& Health, 44(2), 103-120. doi:10.1300/J013v44n02_06

Harned, M. S., Najavits, L. M., \& Weiss, R. D. (2006). Self-harm and suicidal behavior in women with comorbid PTSD and substance dependence. American Journal on Addictions, 15, 392-395. doi:10.1080/10550490600860387

Hochster, H. S. (2008). The power of "p": on overpowered clinical trials and "positive "results. Gastrointestinal Cancer Research: GCR, 2(2), 108-109.

Hughes, T. L., \& Eliason, M. (2002). Substance use and abuse in lesbian, gay, bisexual and transgender populations. The Journal of Primary Prevention, 22(3), 263-297.doi:10.1023/A:1013669705086

Jakupcak, M., Tull, M. T., McDermott, M. J., Kaysen, D., Hunt, S., \& Simpson, T.(2010). PTSD symptom clusters in relationship to alcohol misuse among Iraq and Afghanistan war veterans seeking post-deployment VA health care. Addictive Behaviors, 35(9), 840-843. http://dx.doi.org/10.1016/j.addbeh.2010.03.023

Jepsen, P., Johnsen, S. P., Gillman, M. W., \& Sørensen, H. T. (2004). Interpretation of observational studies, Heart, 90(8), 956-960. doi:10.1136/hrt.2003.017269

Jerome, R. C., \& Halkitis, P. N. (2009). Stigmatization, stress, and the search for belonging in black men who have sex with men who use methamphetamine. Journal of Black Psychology, 35(3), 343-365. doi:10.1177/0095798409333620

Lee, I. C., \& Crawford, M. (2007). Lesbian and bisexual women in the eyes of scientific psychology. Feminism \& Psychology, 17(1), 109-127. doi:10.1177/0959353507073096

Mann, C. J. (2003). Observational research methods. Research design II: Cohort, cross-sectional, and case-control studies. Emergency Medicine Journal, 20, 54-60.

McGinnis, J. M., \& Foege, W. H. (1999). Mortality and morbidity attributable to use of addictive substances in the United States. Proceedings of the Association of American Physicians, 111(2), 109-118. doi:10.1046/j.1525-1381.1999.09256.x

McLaughlin K. A., Hatzenbuehler M. L., Xuan Z., \& Conron, K. J. (2012).Disproportionate exposure to early-life adversity and sexual orientation disparities in psychiatric morbidity. Child Abuse $\mathcal{E}$ Neglect, 36, 645-655. http://dx.doi.org/10.1016/j.chiabu.2012.07.004 
Merline, A. C., O'Malley, P. M., Schulenberg, J. E., Bachman, J. G., \& Johnston, L. D.(2004). Substance use among adults 35 years of age: Prevalence, adulthood predictors, and impact of adolescent substance use. American Journal of Public Health, 94(1), 96-102. doi:10.2105/AJPH.94.1.96

Murray, R. P., Istvan, J.A., Daniels, K., \& Beaudoin, C. M. (1998). Alcohol and morbidity in the Lung Health Study. Journal of Studies on Alcohol, 59, 250-257. http://dx.doi.org/10.15288/jsa.1998.59.250

National Center on Addiction and Substance Abuse (CASA). (2000). No place to hide: Substance abuse in mid-size cities and rural America. New York, NY: Columbia University.

New York City Department of Health and Mental Hygiene. (2008-2013). New York City Community Health Survey. Retrieved from https://www1.nyc.gov/site/doh/data/data-sets/community-healthsurvey-public-use-data.page

Paschall, M. J., Freisthler, B., \& Lipton, R. I. (2005). Moderate alcohol use and depression in young adults: findings from a national longitudinal study. American Journal of Public Health, 95(3), 453-457.

Pathela, P., Hajat, A., Schillinger, J., Blank, S., Sell, R., \& Mostashari, F. (2006).Discordance between sexual behavior and self-reported sexual identity: A population-based survey of New York City men. Annals of Internal Medicine, 145(6), 416-425. doi:10.7326/0003-4819145-6-200609190-00005

Redonnet, B., Chollet, A., Fombonne, E., Bowes, L., \& Melchior, M. (2012). Tobacco, alcohol, cannabis and other illegal drug use among young adults: The socioeconomic context. Drug and Alcohol Dependence, 121(3), 231-239.http://dx.doi.org/10.1016/j.drugalcdep.2011.09.002

Regier, D. A., Farmer, M. E., Rae, D. S., Locke, B. Z., Keith, S. J., Judd, L. L., \&Goodwin, F. K. (1990). Comorbidity of mental disorders with alcohol and other drug abuse. Results from the Epidemiologic Catchment Area (ECA) Study. The Journal of the American Medical Association, 264(19), 2511-2518. doi:10.1001/jama.1990.03450190043026

Rinne, T., De Kloet, E. R., Wouters, L., Goekoop, J. G., DeRijk, R. H., \& van den Brink,W. (2002). Hyperresponsiveness of hypothalamicpituitary-adrenal axis to combined dexamethasone/corticotropinreleasing hormone challenge in female borderline personality disorder subjects with a history of sustained childhood abuse. Biological Psychiatry, 52(11), 1102-1112. http://dx.doi.org/10.1016/S0006-3223(02)01395-1 
Roberts, S. J., \& Sorensen, L. (1999). Health related behaviors and cancer screening of lesbians: Results from the Boston Lesbian Health Project. Women's Health, 28, 1-12. doi:10.1300/J013v28n04_01 Substance Abuse and Mental Health Services Administration (SAMHSA). (2014). Results from the 2013 National Survey on Drug Use and Health: Summary of National Findings. Retrieved from http://www.samhsa.gov/data/sites/default/files/NSDUHresultsPDF WHTML2013/Web/NSDUHresults2013.pdf

Vandenbroucke, J. P., von Elm, E., Altman, D. G., Gotzsche, P. C., Mulrow, C. D.,Pocock, S. J. . . Egger, M. (2007). Strengthening the reporting of observationalstudies in epidemiology (STROBE): Explanation and elaboration. Epidemiology, 18(6), 805-835. doi:10.7326/00034819-147-8-200710160-00010-w1

Windle, M., Mun, E. Y., \& Windle, R. C. (2005). Adolescent-to-young adulthood heavy drinking trajectories and their prospective predictors. Journal of Studies on Alcohol, 66(3), 313-322. http://dx.doi.org/10.15288/jsa.2005.66.313 
Table 1

Correlational Matrix: Age, Annual Household Income, Race, and History of Depression and Alcohol Usage

\begin{tabular}{|c|c|c|c|c|c|}
\hline & Age & Race & $\begin{array}{l}\text { Annual } \\
\text { Income }\end{array}$ & $\begin{array}{l}\text { History of } \\
\text { Depression }\end{array}$ & $\begin{array}{c}\text { Alcohol } \\
\text { Use }\end{array}$ \\
\hline Age & 1 & & & & \\
\hline Race & -0.25 & 1 & & & \\
\hline Annual Income & 0.194 & -0.316 & 1 & & \\
\hline $\begin{array}{l}\text { History of } \\
\text { Depression }\end{array}$ & 0.05 & 0.062 & 0.105 & 1 & \\
\hline Alcohol Use & -0.215 & 0.019 & -0.021 & -0.104 & 1 \\
\hline
\end{tabular}


Table 2

Correlational Matrix: Age, Annual Household Income, Race, and History of Depression and Tobacco Usage Race

\begin{tabular}{lccccc}
\hline Age & Age & Race & $\begin{array}{c}\text { Annual } \\
\text { Income }\end{array}$ & $\begin{array}{c}\text { History of } \\
\text { Depression }\end{array}$ & $\begin{array}{c}\text { Tobacco } \\
\text { Use }\end{array}$ \\
\hline Race & -0.2176122 & 1 & & & \\
Annual & 0.10914793 & -0.344 & 1 & \\
Income & & & & \\
$\begin{array}{l}\text { History of } \\
\text { Depression }\end{array}$ & 0.10556727 & -0.088 & 0.183 & 1 & \\
Tobacco Use & 0.07210143 & -0.216 & 0.003 & -0.113 & 1 \\
\hline$n=114$ & & & & & \\
\hline
\end{tabular}


Table 3

Regression Statistics: Alcohol Use

\begin{tabular}{|c|c|}
\hline Regression & Statistics \\
\hline Multiple $R$ & 0.237 \\
\hline$R$ Squared & 0.056 \\
\hline Adjusted $R$ Squared & 0.049 \\
\hline Standard Error & 1.053 \\
\hline Observations & 509 \\
\hline
\end{tabular}


Table 4

Regression Statistics: Tobacco Use

\begin{tabular}{|c|c|}
\hline Regression & \\
\hline Multiple $\boldsymbol{R}$ & 0.2164 \\
\hline$R$ Squared & 0.0468 \\
\hline Adjusted $R$ Squared & 0.0383 \\
\hline Standard Error & 7.8639 \\
\hline Observations & 114 \\
\hline
\end{tabular}

